\title{
Assessment of management effectiveness of structural units of a vertically integrated oil company
}

\author{
Larisa Rudneva ${ }^{1}$, Olga Rudenok $^{1, *}$, and Natalya Zonova ${ }^{1}$ \\ ${ }^{1}$ Tyumen Industrial University, 625000, 38, Volodarsky st., Tyumen, Russia
}

\begin{abstract}
The article discusses the issues of assessing the effectiveness of managing structural units of a vertically integrated oil company (VIOC). The features are identified and the effectiveness of the management of VIOC structural units in the context of individual business segments is assessed; the main problems in their management are identified. Using the results of the study will allow a more reasonable approach to determining the directions of increasing the efficiency of managing the structural divisions of the oil company and will be useful in identifying and developing priorities for the strategic development of VIOC.
\end{abstract}

\section{Introduction}

A specific feature of the modern oil industry is the predominance of oil companies in it, which have chosen the strategy of vertical integration as a priority development strategy. This strategy allows oil companies to expand their activities, control the entire production process, improve the quality level of final products, and strengthen the company's position on the market in market economy conditions. The dominant position of the VIOC is facilitated primarily by the realization of economies of scale, which is manifested in cost reduction per unit of output (per tonne of oil produced). However, the rapid development of vertically integrated structures in the Russian oil industry has pushed the issues of effective management of their constituent structural divisions into the background.

Building and improving vertical integration is possible only in the conditions of effective management of their structural divisions. The search for ways to improve management efficiency is not possible without conducting a comprehensive assessment of the existing management practices of structural divisions of the VIOC, studying the features of management and identifying factors that affect the level of its effectiveness.

The purpose of this work is to develop theoretical and methodological approaches to improving the strategic management of structural divisions of a vertically integrated oil company.

\footnotetext{
*Corresponding author: rudenokov@tyuiu.ru
} 


\section{Materials and methods}

The theoretical and methodological basis of the research is the works of scientists and practitioners in the field of strategic management of vertically integrated oil companies. The information base of the study was made up of statistical materials reflecting the activities of the VIOC.

The research was conducted using general scientific methods and techniques, such as scientific abstraction, comparative and logical analysis and synthesis, structural-level approach, methods of economic and statistical analysis, as well as factor and cluster analysis, the method of rating assessments.

\section{Results and discussion}

Vertically integrated oil companies include many structural divisions in various business segments that have distinctive features related to the specialization of production activities, with differences in the degree of decentralization, the level and structure of the company's cash flows, geographical location, availability of production resources, etc. [1]. In accordance with this, the evaluation of management effectiveness for each structural division should take into account these features. This determines the need to use a differentiated approach to assessing the effectiveness of management of structural divisions within the VIOC. The possibility of applying this approach is provided by the balanced scorecard (BSC) developed by R. Kaplan and D. Norton [2, 3]. In contrast to the traditional approach, this system is based on key performance indicators (KPI) that reflect the specifics of the VIOC structural divisions and affect the final results of the company as a whole [4, 5]. The basis for determining the key performance indicators that are part of the BSC is the Strategic Development Programs of the VIOC. This approach makes it possible to assess the effectiveness of management of structural divisions by comparing the results of their current activities with the company's strategic development goals [5-7].

In accordance with the proposed methodological approach, the assessment of the effectiveness of management of structural divisions within the VIOC includes seven consecutive stages: 1) clarification of key performance indicators for business segments characteristic of the VIOC [5]; 2) formation of the BSC that most fully reflect the specifics of the VIOC structural divisions' activities in the context of business segments, based on KPIs [8]; 3) determination of reference and criteria values for each KPI and distribution of their actually achieved values across ranges of values; 4) construction of a point scale of evaluation and ranking of KPIs in accordance with the ranges of reference values; 5) calculation of integrated KPI values for each evaluation area; 6) building profiles of structural divisions; 7) conducting a plan-fact analysis and identifying "bottlenecks" in the management of structural divisions.

The difference between the proposed methodology is the use of a matrix approach to building the profiles of structural divisions according to the ratio of their management efficiency levels and their contribution to the implementation of the overall strategy for the VIOC development [9]. This allows a more reasonable approach to the study of the effectiveness of management of structural divisions. The matrix "Efficiency of management of VIOC structural divisions" consists of nine quadrants, united depending on the ratio of the levels of management efficiency of individual structural divisions and their contribution to the implementation of the overall strategy for the VIOC development in four zones (table $1)$. 
Table 1. Zones of the Matrix of efficiency of management of structural divisions of the VIOC

\begin{tabular}{|c|l|}
\hline Matrix zone & \multicolumn{1}{|c|}{ Zone characteristic } \\
\hline $\begin{array}{c}\text { Zone 1. Level of efficiency of } \\
\text { management of structural } \\
\text { divisions is high }\end{array}$ & $\begin{array}{l}\text { It is determined by the high level of integrated KPIs of structural } \\
\text { divisions and their high level of contribution to the } \\
\text { implementation of the overall strategy of VIOC development in } \\
\text { the context of individual business segments. Indicates a high } \\
\text { level of efficiency of management of structural divisions. }\end{array}$ \\
\hline $\begin{array}{c}\text { Zone 2. Level of efficiency of } \\
\text { management of structural } \\
\text { divisions is above the average }\end{array}$ & $\begin{array}{l}\text { It is determined by the average level of integrated KPIs of } \\
\text { structural divisions and the high or average level of their } \\
\text { contribution to the implementation of the overall development } \\
\text { strategy of VIOC. Divisions have a number of opportunities to } \\
\text { improve their management efficiency in the future. }\end{array}$ \\
\hline $\begin{array}{c}\text { Zone 3. Level of efficiency of } \\
\text { management of structural } \\
\text { divisions is below the average }\end{array}$ & $\begin{array}{l}\text { It is determined by the average level of integrated KPIs of } \\
\text { structural divisions and the low or average level of their } \\
\text { contribution to the implementation of the overall development } \\
\text { strategy of VIOC. This zone indicates the uncertainty of the } \\
\text { future development of structural divisions, despite their effective } \\
\text { performance in the current period. }\end{array}$ \\
\hline $\begin{array}{c}\text { Zone 4. Level of efficiency of } \\
\text { management of structural } \\
\text { divisions is low }\end{array}$ & $\begin{array}{l}\text { It is determined by the low level of integrated KPIs of structural } \\
\text { divisions and the low level of their contribution to the } \\
\text { implementation of the overall development strategy of VIOC. } \\
\text { The zone is characterized by the inability of structural divisions } \\
\text { to carry out activities, and as a result - their inability to work } \\
\text { effectively in the future. Requires immediate decision-making. }\end{array}$ \\
\hline
\end{tabular}

The main parameters for assessing the contribution of structural divisions to the implementation of the overall development strategy of VIOC include indicators that are common to VIOC and reflect the share of the contribution of structural divisions to the formation of: the final financial results of the oil company; industry indicators of VIOC; the presence of the oil company at the market $[2,8]$.

In general, the presented methodological approach fairly objectively solves the problems of evaluating and improving the efficiency of management of structural divisions of the vertically integrated oil company.

The presented methodological approach was tested on the example of one of the Russian vertically integrated oil companies, whose value chain includes the entire cycle of the main business processes of the oil industry [9]. The strategic goal of this VIOC is to strengthen its position in the Russian oil and gas sector as a reliable company with a stable financial position and production development prospects, based on best practices in the field of efficient use of technologies and equipment, social and environmental responsibility.

In the course of the research, the key performance indicators for business segments that are specific to this VIOC were clarified [8]. The results of the evaluation carried out using the presented methodological approach indicate a high efficiency of management of structural divisions that are part of the VIOC. There is a high consistency of management of structural divisions with the overall strategy of the company's development (Fig. 1). 


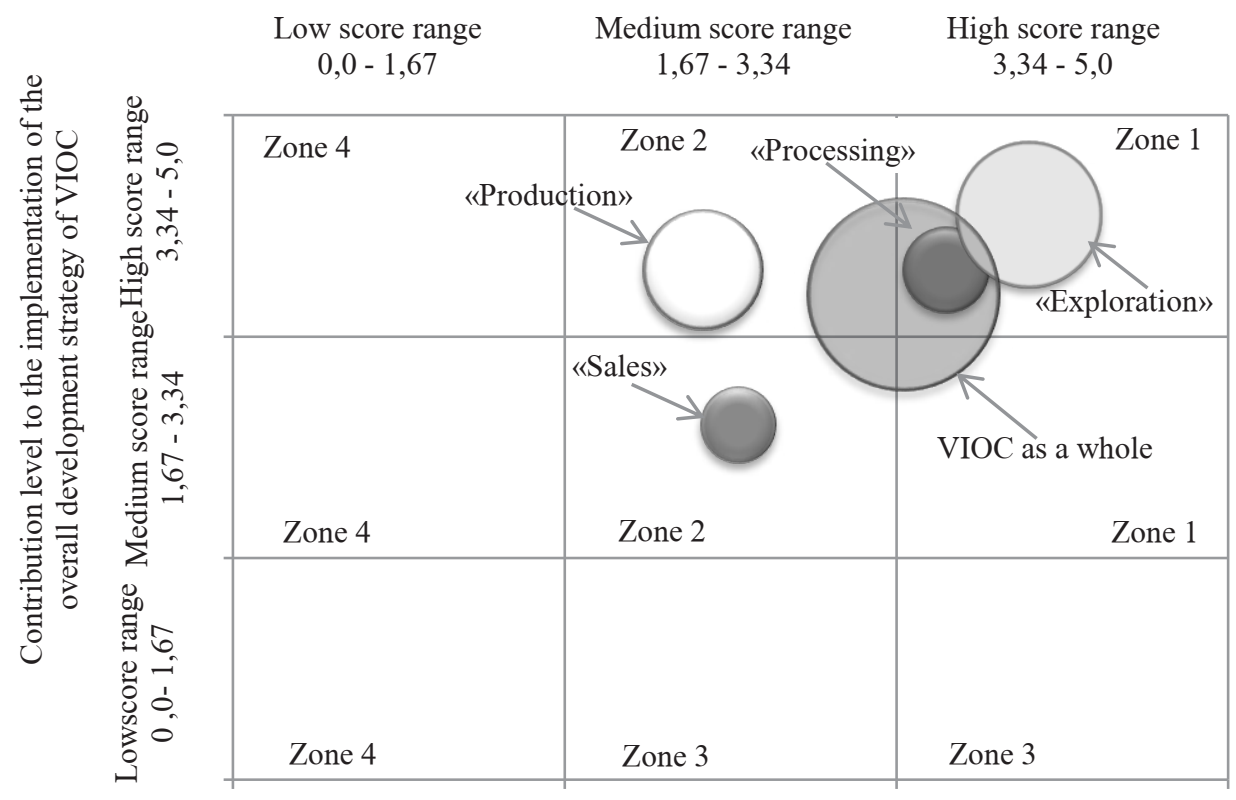

The level of management effectiveness of structural units

Fig. 1. Management effectiveness matrix of the structural subdivisions of vertically integrated companies by business segments, 2018

The level of efficiency of management of structural divisions in the business segments "Exploration" and "Processing" in terms of the ratio of indicators of efficiency of management of structural divisions and their contribution to the implementation of the development strategy of VIOC is high (Zone 1). A negative impact on the level of overall management efficiency of the structural divisions that are part of VIOC was caused by an insufficiently high level of management efficiency of the structural divisions in the business segments "Production" and "Sales" (Zone 2). The main reasons for this situation of structural divisions in these business segments are the following: reduction in oil production due to the OPEC+ agreement; not specifying the strategic guidelines for the development of VIOC in the field of production and sales, since the main direction of sales of oil and petroleum products for the company is export.

A detailed study of the effectiveness of management of structural divisions by business segments based on plan-fact analysis revealed that in 2018, compared to 2017, there is an increase in the efficiency of management of structural divisions in the business segments "Exploration", "Production" and "Processing". In the "Sales" business segment, there is a decrease in the level of management efficiency of structural divisions.

Improving the efficiency of management of structural divisions in the business segment "Exploration" is due to increased efficiency of cost management, $\mathrm{R} \& \mathrm{D}$, and exploration drilling (Fig. 2). This is evidenced by the increase in the actual level of success of exploratory drilling over planned ones, with the constant dynamics of the share of new fields in total hydrocarbon production. A negative impact on the level of management efficiency in the exploration segment was caused by a decrease in management efficiency in terms of prospecting and exploration operations. 


\section{Integrated coefficient of achieving the KPI of the planned levd in $2017=102.43 \%$}

Share of new deposits in total carbon production
Integrated coefficient of achieving the KPI of the planned level in $2018=103,42 \%$

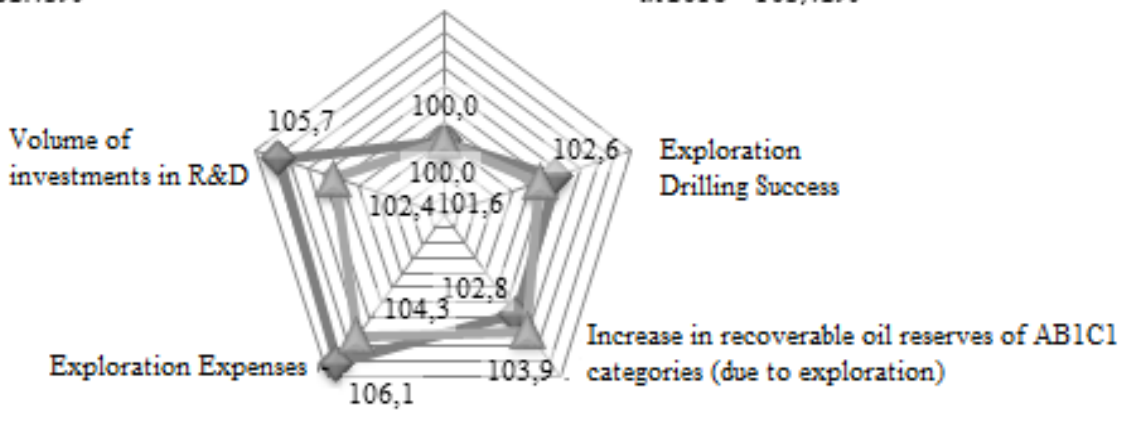

* Planned level achievement rate, 2018

$\rightarrow$ Planned level achievement rate, 2017

Fig. 2. Plan-fact analysis of key performance indicators for the "Exploration" business segment for 2017-2018.

In the "Production" business segment increase of efficiency of management of structural divisions is due to the improvement of efficiency of quality management of oil production (Fig. 3) as a result of: improvment of the level of disposal of drilled sludge, growth in the number of active wells in percent of the operating well stock and increase the production volume of associated petroleum gas. The main directions of improving the quality of oil production were the development of infrastructure for the collection and use of associated petroleum gas; modernization and construction of modern oil sludge disposal sites; measures to optimize the operation of the well stock and development systems; implementation of a wide range of geological and technical measures.

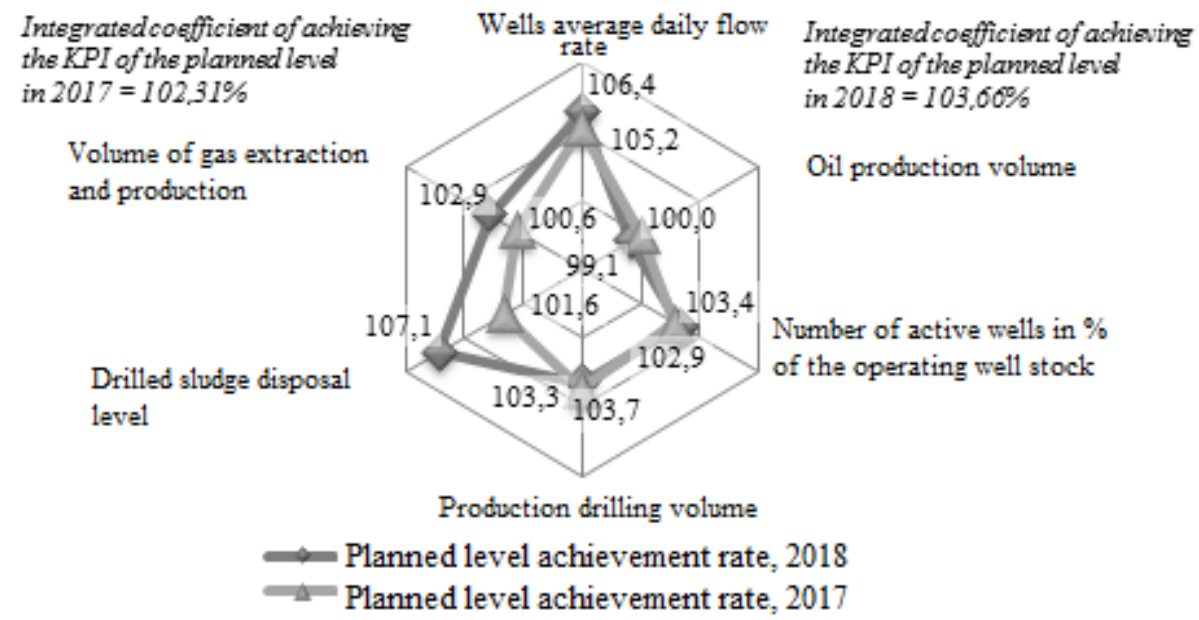

Fig. 3. Plan-fact analysis of key performance indicators for the "Production" business segment for 2017-2018.

Improvement of the efficiency of management of structural divisions in the oil refining sector is due to an increase in the efficiency of processing quality management (Fig. 4). 
This is evidenced by the ratio of the growth rates of the actual values of the output of light oil products and the share of high-octane gasoline in the total output over the growth rates of the production of oil products relative to the planned values by years. There is also increase of management efficiency in the sphere of processing and utilization of associated petroleum gas, which is reflected in increasing volumes of associated gas by developing gas processing plant, the annual modernization of production capacities, and introducing advanced technology and equipment.

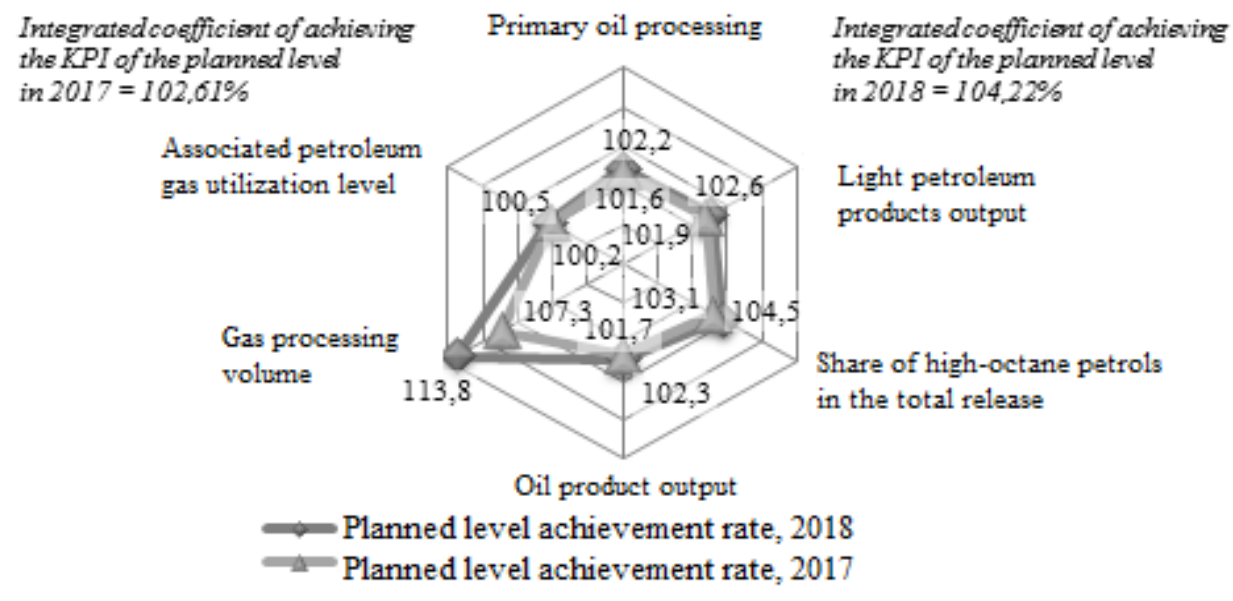

Fig. 4. Plan-fact analysis of key performance indicators for the "Processing" business segment for 2017-2018.

The decrease in the efficiency of management of structural divisions in the business segment "Sales" (Fig. 5) is due to a decrease in the efficiency of management in terms of product policy.

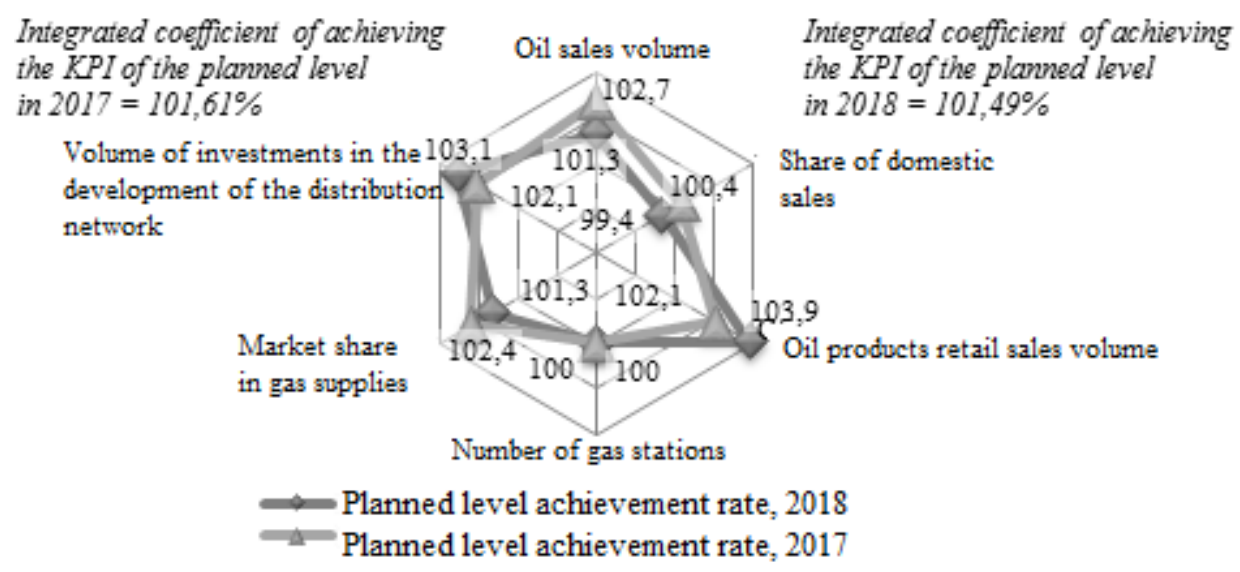

Fig. 5. Plan-fact analysis of key performance indicators for the "Sales" business segment for 20172018.

This was reflected in a decrease in oil sales, a reduction in the share of sales of petroleum products to the domestic market and the company's share in gasoline supplies to the domestic market. It is important to note the influence of restrictive factors on sales activities, which affects the implementation of the company's development strategy. 
Despite this, work is ongoing to develop sales at the domestic market through the implementation of a program for the development of the retail network. This indicates an increase in the effectiveness of sales management in the implementation of retail sales policy.

According to the results of the study, the following conclusions can be drawn:

- management of structural divisions at the strategic level is carried out by the parent company in the context of controlled business segments and consists in determining the priorities of activities in accordance with the selected strategy for the VIOC development;

- in general, there is a high consistency of the effectiveness of management of structural divisions with the overall development strategy. The management of the current activities of structural divisions can be considered effective, despite the impact of limiting external factors;

- the implementation of the existing strategy should be supported based on internal capabilities and external factors, which will improve the effectiveness of the VIOC strategic management.

\section{Conclusions}

Summarizing the above and based on the results of the implementation of the existing development strategy of the VIOC, it can be stated that the further development of the company should consist in expanding the production and sales of petroleum products, developing new market sectors and developing a sales network at the domestic market. This implies choosing a marketing business strategy as the company's development strategy. Using a marketing approach will allow the following: to clarify the company's strategic development goals; to determine production and sales volumes in accordance with market needs; to manage intra-corporate flows between structural divisions more reasonably; to meet existing needs in existing markets more fully and to identify new potential sales markets.

\section{References}

1. E. Yu. Novikova, Current issues of Economics and Management, 1, 43-49 (2016)

2. Robert Kaplan, David P. Norton, The Balanced Scorecard. From strategy to action (2003)

3. R. S. Kaplan, D. P. Norton, Harvard Business Review, 1, 70 (1992)

4. Parmenter David, Key performance indicator. Development, implementation and application of critical indicators (2009).

5. T. V. Ponomarenko, I.A. Akinina, A.N. Uvazhaev, A.A. Battalova, Notes of the Mining Institute, 201, 219-227 (2013).

6. N. L. Kaznacheeva, A. V. Morgunov, Bulletin of the Tomsk State University, 326, 137 139 (2009)

7. T. G. Ryzhakina, Bulletin of the Tomsk State University, 323, 285-287 (2009)

8. A. A. Ilyas, A. E. Tasmukhanova, El. Sc. journal Oil and Gas Engineering, 3, 543-575 (2015)

9. N. V. Zonova, O. V. Rudenok, O. V. Tarasova, Moscow Economic Journal, 12, 702$711(2019)$ 